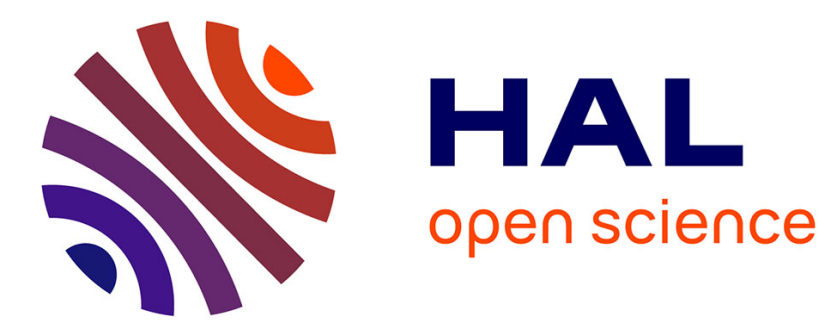

\title{
Modeling of the deep granular bed clogging by nanoparticles
}

Loïc Wingert, N. Bardin-Monnier, A. Charvet, D. Bémer, Dominique Thomas

\section{To cite this version:}

Loïc Wingert, N. Bardin-Monnier, A. Charvet, D. Bémer, Dominique Thomas. Modeling of the deep granular bed clogging by nanoparticles. Separation and Purification Technology, 2017, 176, pp.384 394. 10.1016/j.seppur.2016.12.013 . hal-01432076

\section{HAL Id: hal-01432076 https://hal.science/hal-01432076}

Submitted on 19 Jan 2017

HAL is a multi-disciplinary open access archive for the deposit and dissemination of scientific research documents, whether they are published or not. The documents may come from teaching and research institutions in France or abroad, or from public or private research centers.
L'archive ouverte pluridisciplinaire HAL, est destinée au dépôt et à la diffusion de documents scientifiques de niveau recherche, publiés ou non, émanant des établissements d'enseignement et de recherche français ou étrangers, des laboratoires publics ou privés. 


\title{
Modeling of the deep granular bed clogging by nanoparticles
}

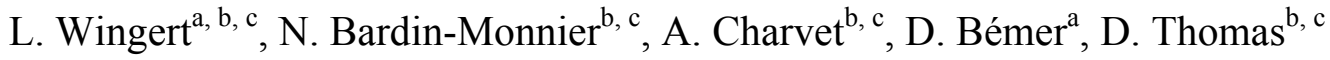 \\ ${ }^{\text {a } I n s t i t u t ~ N a t i o n a l ~ d e ~ R e c h e r c h e ~ e t ~ S e ́ c u r i t e ́ ~(I N R S), ~ F-54519, ~ V a n d œ u v r e-l e ̀ s-N a n c y, ~ F r a n c e ~}$ \\ ${ }^{\mathrm{b}}$ Université de Lorraine, Laboratoire Réactions et Génie des Procédés, UMR 7274, F-54000, \\ Nancy, France
}

${ }^{\mathrm{c}}$ CNRS, Laboratoire Réactions et Génie des Procédés, UMR 7274, F-54000, Nancy, France

Corresponding author: loic.wingert@inrs.fr

\begin{abstract}
Nanoparticles aerosols are a potential health hazard and are increasingly used in industry today. Effective means for their filtration to avoid occupational exposure are necessary. Granular bed filtration exhibits interesting properties in terms of ultrafine particle collection efficiency or retention capacity, which could make them a good alternative to the fiber filters commonly used in industry today. Being able to predict changes to their collection efficiency and pressure drop during clogging appears essential for the design, optimization and control of the filtration process. To meet these needs, this study presents a predictive model for the different phases of deep-bed clogging. The model developed successfully describes changes to collection efficiency and pressure drop using equivalent collector diameters. Microscopic observations showed these equivalent diameters to be compatible with considering the deposit as a uniform spherical layer all over the collector's surface. The predictions of the model agreed well with data from several clogging experiments for which various operating conditions were used, i.e., different collector's diameters, particulate materials or superficial velocities.
\end{abstract}

\section{Keywords}

Granular Bed Filtration, Aerosol, Nanoparticles, Model, Efficiency, Pressure Drop 


\section{Introduction}

Due to the growing awareness that nanoparticles may represent a public health issue, through directive 2008/50/EC the European Union has imposed a reduction in the permissible concentrations of airborne ultrafine particles. Diesel engines are one of the best-known sources of these particles, but they could also represent an occupational health issue. Indeed, ultrafine particles are generated in the workplace by many manufacturing processes such as surface processing (thermal spraying), machining (drilling, grinding, etc.), combustion, and similar activities. To comply with regulations, nanoparticles must be removed from the exhaust air produced by these processes. Currently, the most efficient and widely used de-dusting methods involve filtration through pleated fiber filters. These filters are initially very efficient but rapidly exhibit a strong increase of the pressure drop because of quick, and sometimes irreversible, clogging. Their replacement can be expensive and this factor could lead companies to eliminate their use or to reduce ventilation capacities, impacting the outdoor and indoor air quality, respectively. For these reasons, alternative means of nanoparticle filtration have become a significant field of interest in the past few years. Among the possible alternatives, granular beds exhibit interesting properties in terms of ultrafine particle collection efficiency, operation time, dust retention capacity, hot gas cleaning, cost, and robustness. Furthermore, the clogging of granular beds by nanoparticles may be reversible [1].

During the filtration process, the structure of the granular bed is continuously modified as a result of particle deposition. These modifications alter the flow field, which in turn affects the pressure drop and the transport of particles on the collector's surface. This pattern makes the process inherently nonsteady, and thus complicates prediction of its dynamic behavior. Nevertheless, this behavior must be accurately predicted if filtration processes using this type of device are to be designed, optimized and controlled.

Over the past four decades, numerous investigations have attempted to model the transient behavior of granular beds during filtration. One of the first models was developed by Herzig et al. [2] who proposed a procedure to solve the macroscopic equations describing the filter's transient behavior. 
These relationships, based on the particle mass balance during the filtration process, can be used to establish an equation for the deposition rate, i.e., the variation over time of the mass deposited at a given depth in the granular bed. Herzig et al. expressed this variation as a function of the filter coefficient, which can be defined as the probability of particle collection per depth unit. As this coefficient is not a constant throughout clogging, the modeling approach consisted in finding the expression describing the ratio between the instantaneous filter coefficient (or collection efficiency) and its initial value. The pressure drop over time can be calculated by applying a similar method to find the equation describing the ratio between the instantaneous pressure drop and its initial value. One method through which such expressions can be established is to develop empirical correlations for a given clogging configuration [3,4]. For airborne particles larger than $1 \mu \mathrm{m}$, three main studies established more general correlations for filtration. In the first of these, Walata et al. [5] observed that the functions linking the filter coefficient ratio or the pressure drop ratio to the amount deposited can be expressed by equations having the same functional form. This equation depends on a small number of coefficients that must be found for different clogging configurations. To determine the values of these coefficients, the authors conducted several experiments changing only the depth of the granular bed. They fitted these data to obtain different pairs of coefficients, assuming a uniform deposit at each depth. This assumption is more valid at shallower depths, thus the correct coefficient pair can be obtained by extrapolation to a depth of zero. The same procedure was used by Takahashi et al. [6] to correlate the empirical constants with operating variables such as the Stokes number or the interception number. Subsequently, Jung and Tien [7] calculated the bed depth beyond which the uniform deposition assumption was no longer valid under their operating conditions. In their case, it was no longer necessary to extrapolate to determine the correlations. Furthermore, their correlations were established on the basis of experiments conducted with a wider range of filtration regimes than in the previous studies.

Although physically realistic and giving a good idea of the trends that filter clogging follows over time, these approaches are not predictive and do not provide any insight into the mechanisms involved in particle capture. 
Another approach that can be used to model clogging is to calculate the pressure drop over time by modifying selected parameters (collector diameter, porosity, etc.) in the Kozeny-Carman law while assuming a specific geometry of the deposit within the granular bed. Rational models based on this approach specifically describe the influence of the deposited particles on the filter's transient behavior. O’Melia and Ali [8] developed a pressure drop and efficiency model describing the ripening phase, i.e., the phase during which efficiency of liquid filtration improves with clogging. To develop this model, they used three particles sizes $(0.1,1$ and $7.6 \mu \mathrm{m})$ and assumed that the deposited particles act as additional collectors, thus improving the filter's collection efficiency. They calculated the pressure drop by taking the alterations to the collector's specific area into account in the Kozeny-Carman law. Although the description of the deposited particles as additional collectors seems to be realistic, the model had a very limited predictive power. Indeed, some parameters such as the single-particle collection efficiency, the adhesion factors or an arbitrary empirical constant in the pressure drop calculation had to be determined from experimental measurements and could not be readily transposed from one case to another [4]. Furthermore, the spatial arrangement of the deposit provided by this model was not realistic enough to be able to predict the decrease in media permeability. To overcome these issues, Tien et al. [9] developed a hybrid model for the liquid filtration of $6-\mu \mathrm{m}$ diameter particles, by splitting the deposition process into two steps. Thus, the deposit was initially considered to form a smooth layer over the grains, and then to gradually obstruct the pore space causing a decrease in the number of pores available to induce flow. To describe these steps, the granular bed was considered as a series of unit bed elements (UBE). Two collector representations were used within the UBEs: the sphere-in-cell described by Happel [10] for the first phase, and the constricted tube presented by Payatakes [11] for the second. This two-phase model can be used to calculate the ratio of the instantaneous filter coefficient to its initial value for application in the procedure developed by Herzig et al. [2]. Through this application, it is possible to solve the macroscopic equations describing the transient behavior of the filter. However, this model is still not predictive because it uses three fitting parameters: the deposit porosity, the amount of deposit before the start of the second phase, and an arbitrary constant. Despite this drawback, this hybrid design can still describe experimentally-observed behavior and provides an order of magnitude. 
For non-Brownian hydrosols, Choo and Tien [12] developed a clogging model using a modified version of the sphere-in-cell collector representation. In their model, a third zone representing a permeable deposited layer of non-uniform thickness was added over the collector's surface. Based on numerical results, the increase in deposition was expressed as the change to the filter coefficient over time in order to solve the macroscopic filtration equations. Although this model only provided fairly good agreement with experimental results, it required no experimental evidence or fitting parameters. In a similar approach, Fichman et al. [13] established a clogging model for aerosols in regimes dominated by interception and inertia, i.e., for micron-sized particles. This model gave good agreement with experimental data. The main difference between the Fichman and Choo/Tien models relies on the assumption of a uniform deposit and, consequently on the thickness of the layer deposited on the collector's surface.

In another study, Choo and Tien [14] developed an algorithm to predict the clogging of a granular medium by non-Brownian hydrosols. This model used the UBE representation, with collectors represented either by sphere-in-cell or by capillaries for efficiency and pressure drop calculations, respectively. The amount of deposit can be used to update the capillary's geometry and thus to run the algorithm for the next time and depth steps. Even though this model has fewer arbitrary parameters, a fitting factor continues to influence the penetration profile, and this factor is difficult to estimate on the basis of experimental results.

All these models often idealize the structure of the granular filters by neglecting the lateral connections between unit collectors within a UBE. Indeed, the original concept of Payatakes [11] assumed collectors to be axially oriented with no links between UBEs. Vigneswaran and Tien [15] proposed a different simulation describing the flow through a granular bed as a flow through a network of randomly interconnected tubes of various sizes. They calculated the flow within this network by applying the effective medium approximation theory [16]. Based on this flow, the amount of deposited particles and the pressure drop can be estimated. The network structure can then be updated by taking instantaneous clogging into account. 
This entire procedure has to be repeated until some tubes become clogged. Despite a lack of comparison with experimental data in the article, the predicted results agreed well with the expected quantitative behavior.

Other types of tools based on aerodynamic analysis were developed to predict deep-bed filtration behavior. For example, Pendse and Tien [17] described clogging by computing the deposition rate and the deposit morphology from analyses of particle trajectories as they entered a constricted tube. For simplicity, only particles with a high and low inertia were considered, their trajectories being rectilinear or coincident with the streamlines, respectively. In another model, Chiang and Tien [18] simulated liquid filtration of non-Brownian particles assuming two other limiting cases: (1) a smooth layer deposition over the collector's surface and (2) individual collected particles acting as additional collectors without neglecting the probability of adhesion. As this work described limiting cases, the authors considered the transient behavior of the filtration process to be a combination of both cases and derived a semi-empirical correlation depending on operating variables which, in some cases, successfully predicted results from independent sources. More recently, Burganos et al. [19] and Skouras et al. [20] developed a 3D simulator for upflow and downflow deep-bed filtration of nonBrownian hydrosols. These authors represented the granular bed by a network of constricted tubes and considered advanced phenomena such as reentrainment of clusters and their redeposition.

This review shows that many models have been developed to predict the transient behavior of deepbed filtration. However, most of them focused on the filtration of non-Brownian hydrosols. Furthermore, only a few of these models are truly predictive and they often require time- and memoryconsuming computations of streamlines and particle trajectories. In this article, based on theoretical considerations, we propose a new modeling principle for changes to the pressure drop and filtration efficiency throughout the granular bed during clogging with Brownian aerosols. 


\section{Materials and methods}

The experimental setup consisted in a 40-mm diameter granular bed composed of stainless steel spherical collectors. Three different collector sizes were used: 1.6, 1 and $0.5 \mathrm{~mm}$ (Figure 1). To ensure that the porosity was as close as possible to that of a random close-packing of spheres $(0.37)$, vibrations were applied all around the beds until the pressure drop was similar to that predicted by the Kozeny-Carman law. These characteristics were maintained unchanged so that the depth of granular beds was approximately $11 \mathrm{~mm}$ in all cases. Static pressure sensors were mounted upstream and downstream of the granular bed to monitor variations of the pressure drop during clogging.

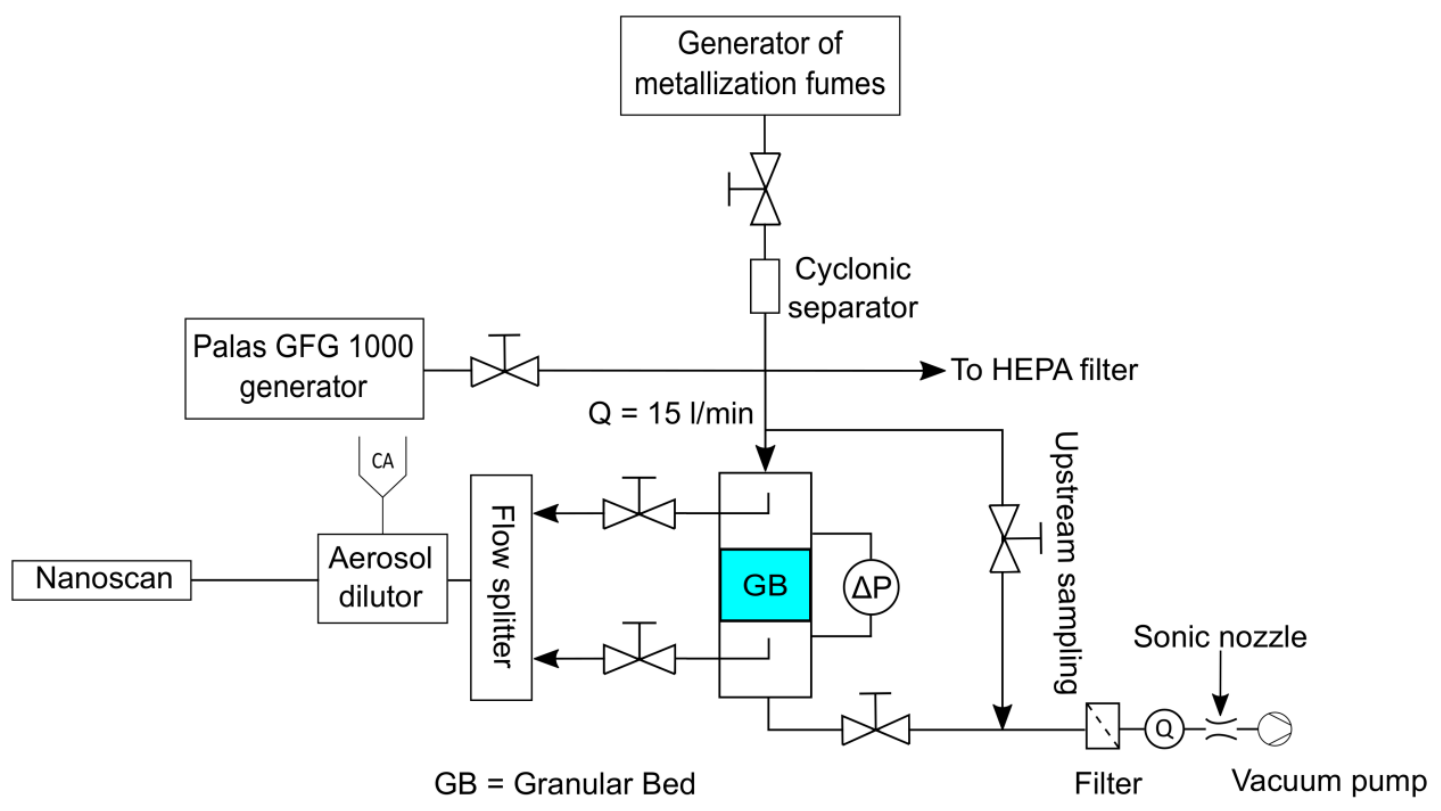

Figure 1 Experimental setup for granular bed clogging

Three different particle materials were used to clog the granular bed: iron, carbon and zinc-aluminum (Zn-Al). The iron and carbon nanoparticles were generated by an electric spark generator (GFG1000, Palas). Their number size distributions were measured by a SMPS (Scanning Mobility Particle Sizer, long DMA + CPC Grimm 5.403) after a dilution stage and fitted to a lognormal model by applying the least squares method (Figure 2). The number median diameters (expressed in electrical mobilityequivalent diameter) were $61.6 \mathrm{~nm}$ for iron particles and $46.1 \mathrm{~nm}$ for carbon particles, and the 
Geometric Standard Deviations (GSD) were 1.65 and 1.56, respectively. The total number concentration was close to $3.3 \times 10^{7} \mathrm{~cm}^{-3}$ for carbon and to $6 \times 10^{6} \mathrm{~cm}^{-3}$ for iron agglomerates.

$\mathrm{Zn}-\mathrm{Al}(85 / 15 \%)$ particles were generated by thermal spraying of an alloy using an electric arc gun (Margarido M25). The aerosol produced was then directed towards a sharp-cut cyclone (BGI SCC 1.829) to remove the micron-sized fraction so that the granular bed was only clogged with the fine fraction. The resulting $\mathrm{Zn}-\mathrm{Al}$ particles presented a number median diameter of $78.3 \mathrm{~nm}(\mathrm{GSD}=1.6)$ and a total number concentration of approximately $2.0 \times 10^{8} \mathrm{~cm}^{-3}$.

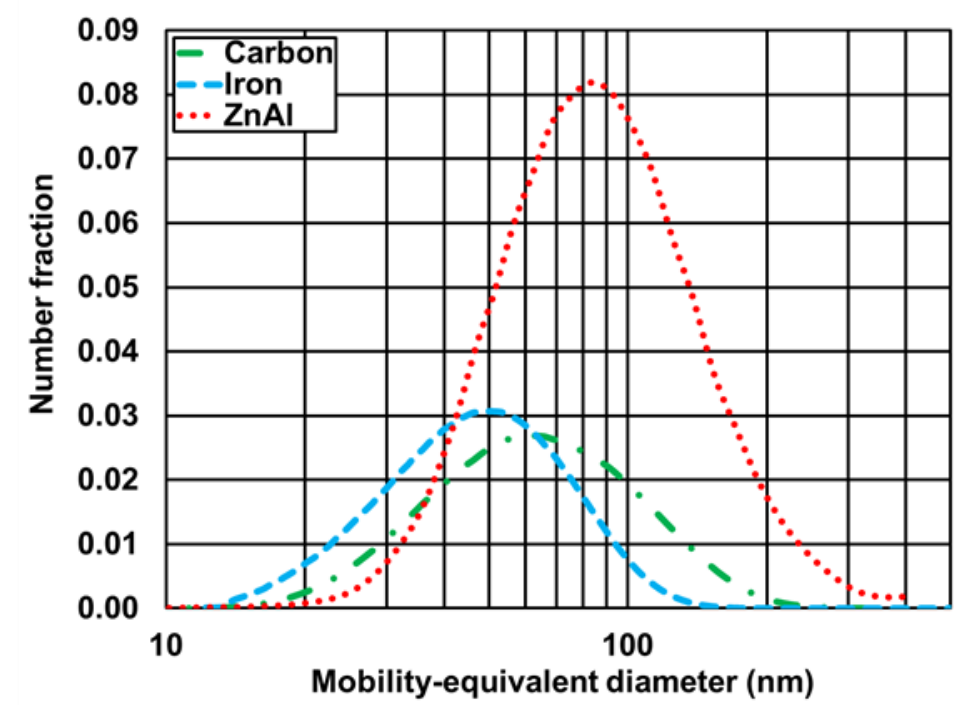

Figure 2 Number particle size distributions for carbon, iron and Zn-Al aerosols

The air flow rate in the system was controlled by a sonic nozzle and measured by a mass flowmeter (TSI 4100). It was set to $15 \mathrm{~L} / \mathrm{min}$ or $5.6 \mathrm{~L} / \mathrm{min}$, corresponding to a superficial velocity of $19.89 \mathrm{~cm} / \mathrm{s}$ or $7.49 \mathrm{~cm} / \mathrm{s}$, respectively. The downstream sampling filter was weighed to determine the total particle mass concentration leaving the granular bed during clogging. Similarly, the mass concentration of the inlet aerosols was determined by weighing particles collected before entering the column. 
All the operating conditions are summarized in the Table 1.

\begin{tabular}{|c|c|c|c|c|}
\hline Experiment & Material & $\begin{array}{c}\text { Superficial velocity } \\
\mathbf{( c m} / \mathbf{s})\end{array}$ & $\begin{array}{c}\text { Mean electrical } \\
\text { mobility-equivalent } \\
\text { diameter (nm) }\end{array}$ & $\begin{array}{c}\text { Collector } \\
\text { diameter } \\
(\mathbf{m m})\end{array}$ \\
\hline 1 & Zn-Al & 19.89 & 78.3 & 0.5 \\
\hline $2(\mathrm{a}, \mathrm{b}, \mathrm{c})$ & Zn-Al & 19.89 & 78.3 & 1 \\
\hline 3 & Zn-Al & 19.89 & 78.3 & 0.5 \\
\hline 4 & Zn-Al & 7.49 & 78.3 & 0.5 \\
\hline 5 & Carbon & 19.89 & 61.6 & 0.5 \\
\hline 6 & Iron & 19.89 & 46.1 & 0.5 \\
\hline
\end{tabular}

Table 1 Operating conditions of the experiments

The particle number size distributions were measured upstream and downstream of the granular bed using a Nanoscan analyzer (3910, TSI) after dilution (VKL100, Palas). These sequential measurements, called cycles, consisted of three 1-min scans upstream of the granular bed followed by three 1-min scans downstream of the column.

The duration between the start of 2 consecutive cycles varied for the different aerosols, it was set at 12 minutes for $\mathrm{Zn}-\mathrm{Al}$ particles and 30 minutes for iron or carbon particles. The reason for this difference was that the total number concentration for the metallization fumes was much higher than the number concentration for carbon and iron aerosols, and consequently the kinetics of clogging was much faster.

The number collection efficiency for the granular bed was determined from the averaged upstream and downstream scans for a sampling cycle. To calculate the mass collected at each time step, the fractional number concentrations measured by the Nanoscan first had to be converted into fractional mass concentrations. 
For a given particle size, i.e., a given channel of the Nanoscan, the fractional mass concentration was computed by applying

$$
\mathrm{C}_{\mathrm{m}, \mathrm{i}}=\frac{\pi * \rho_{\mathrm{p}}}{6} * \mathrm{C}_{\mathrm{n}, \mathrm{i}} * \mathrm{~d}_{\mathrm{v}, \mathrm{i}}^{3}
$$

where $\rho_{\mathrm{p}}$ is the density of the raw material from which particles were generated $\left(5740 \mathrm{~kg} / \mathrm{m}^{3}\right.$ for $\mathrm{Zn}$ $\mathrm{Al}, 2250 \mathrm{~kg} / \mathrm{m}^{3}$ for carbon and $7870 \mathrm{~kg} / \mathrm{m}^{3}$ for iron), $\mathrm{d}_{\mathrm{v}}$ is the volume equivalent diameter, and $\mathrm{C}_{\mathrm{n}}$ is the number concentration measured.

The volume equivalent diameter could then be calculated using the following equation [21]:

$$
\mathrm{d}_{\mathrm{v}}=\mathrm{d}_{\mathrm{me}} *\left(\frac{\rho_{\mathrm{e}}}{\rho_{\mathrm{p}}}\right)^{\frac{1}{3}}
$$

where $d_{m e}$ is the electrical mobility-equivalent diameter measured by the Nanoscan, and $\rho_{e}$ is the effective density of the particles. This effective density was determined using a differential mobility analyzer and an aerosol particle mass analyzer operating in series. Empirical correlations linking the effective density and the electrical mobility-equivalent diameter can be found in the literature for these aerosols $[22,23]$ :

$$
\begin{aligned}
& \rho_{\mathrm{e}, \text { carbon }}=20135 * \mathrm{~d}_{\mathrm{me}}^{-1.02} \\
& \rho_{\mathrm{e}, \mathrm{Zn} / \mathrm{Al}}=40238 * \mathrm{~d}_{\mathrm{me}}^{-0.912} \\
& \rho_{\mathrm{e}, \text { iron }}=10858 * \mathrm{~d}_{\mathrm{me}}^{-0.807}
\end{aligned}
$$

It should be noted that the electrical mobility-equivalent diameter is expressed in nanometers in these expressions so that the unit of measurement of the calculated effective density will be $\mathrm{kg} / \mathrm{m}^{3}$.

Once the fractional mass concentrations upstream and downstream of the granular bed are known, the fractional mass collection efficiency, $\mathrm{E}_{\mathrm{exp}, \mathrm{m}, \mathrm{i}}$, can be calculated by applying:

$$
\mathrm{E}_{\text {exp, } \mathrm{m}, \mathrm{i}}=1-\frac{\mathrm{C}_{\mathrm{m}, \mathrm{i}, \text { down }}}{\mathrm{C}_{\mathrm{m}, \mathrm{i} \text { up }}}
$$

where the subscript i stands for the different measurement channels. 
To overcome the uncertainties introduced by the low resolution of the Nanoscan (13 channels between 10 and $420 \mathrm{~nm}$ ) and the dilution stage, the real upstream mass concentration was determined at each time step using the gravimetric measurement performed upstream of the granular bed $\left(\mathrm{C}_{\mathrm{m}, \mathrm{f}}\right)$.

$$
\mathrm{C}_{\mathrm{m}, \mathrm{i}, \mathrm{up}, \text { real }}=\frac{\mathrm{C}_{\mathrm{m}, \mathrm{i} \text { up }}}{\sum_{\mathrm{i}=1}^{\mathrm{n}} \mathrm{C}_{\mathrm{m}, \mathrm{i}, \mathrm{up}}} \cdot \mathrm{C}_{\mathrm{m}, \mathrm{f}}
$$

Finally, the total mass collected at each time step was determined:

$$
\mathrm{m}_{\mathrm{p}, \mathrm{T}}=\mathrm{Q} \cdot \mathrm{dt} \cdot \sum_{\mathrm{i}=1}^{\mathrm{n}} \mathrm{C}_{\mathrm{m}, \mathrm{i}, \mathrm{up}, \mathrm{real}} \cdot \mathrm{E}_{\mathrm{exp}, \mathrm{m}, \mathrm{i}}
$$

where $\mathrm{Q}$ is the volumetric air flow rate.

\section{Clogging model}

\subsection{Presentation of the model}

To predict how collection efficiency and pressure drop change during clogging, and as a consequence to predict the temporal variation in the mass collected, we developed a model by considering the deposit of Brownian particles as a spherical shell all over the collector's surface. This assumption has been widely used in the clogging models presented in the introduction $[9,13]$. To validate it, carbon nanoparticles deposited under predominant Brownian diffusion on a line of magnetic beads were observed under a microscope. In this type of system, the flow field around the collectors will not be influenced by any support. Figure 3 shows that the deposit is elliptical rather than spherical, due to the influence of contact points. Nevertheless, this elliptic morphology was observed all around the collectors by rotating the beads line and thus the shape of the deposit can be considered as uniform.

Furthermore, the apogee of the elliptical deposit is only slightly higher than the diameter of the collector, permitting to keep a rather good sphericity of the collector and its deposit. Thus, we made the simplifying assumption of a spherical deposit layer implying a constant thickness of deposit. For more detailed information on the morphology of nanoparticles deposits on spherical collectors, readers can refer to Charvet et al. (2017) [24]. 


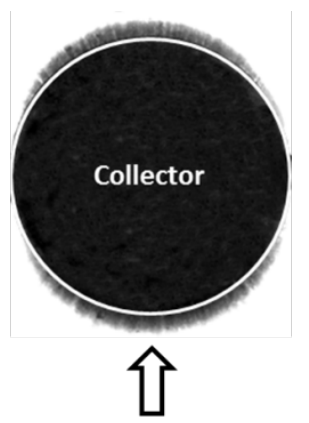

Flow direction

\section{Figure 3 Nanoparticles deposited on a spherical collector}

The uniformity of the deposit allowed us to define equivalent collector diameters depending on the mass collected. These diameters could then be used in the models of initial pressure drop and collection efficiency.

The experimental data obtained from clogging experiments show three phases in the traces for pressure drop (Figure 4 left panel) and efficiency (Figure 4 right panel).
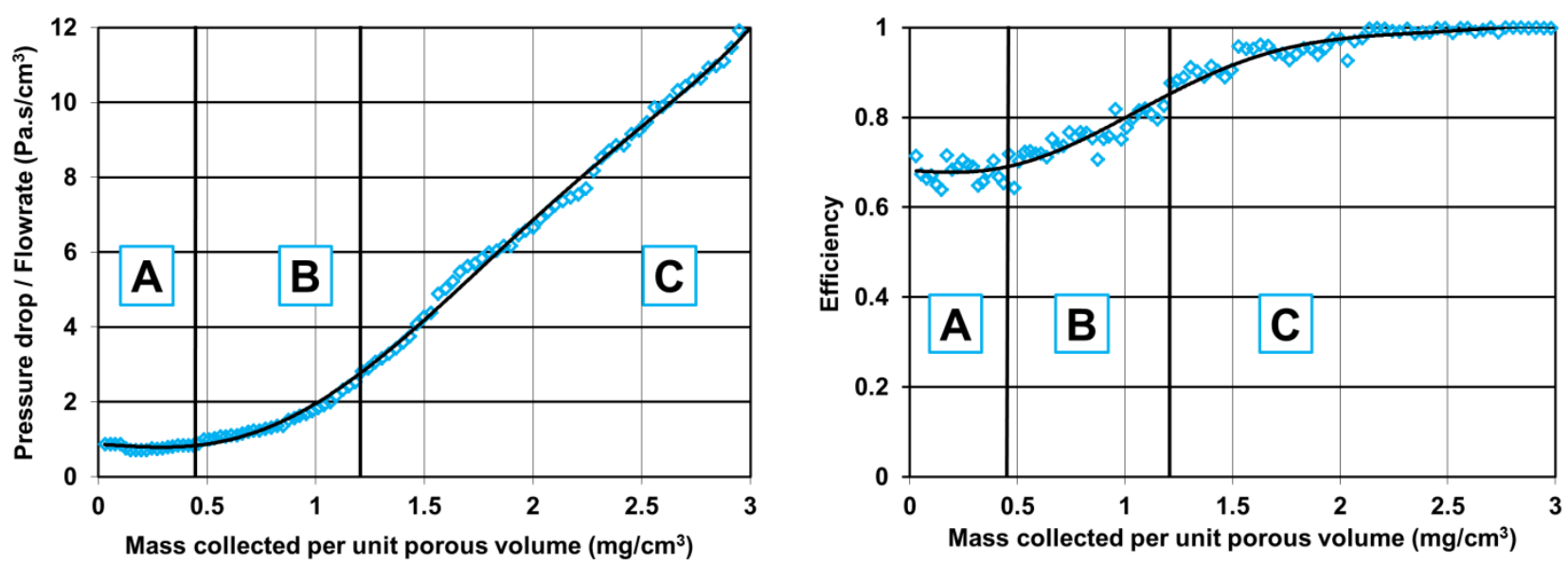

Figure 4 Pressure drop (left panel) and efficiency (right panel) over time for a granular bed composed of 0.5-mm-diameter collectors clogged with iron agglomerates

Of these three phases, Phase $\mathbf{C}$ corresponds to the beginning of the surface filtration marked by a linear increase in pressure drop. One can also notice that the transition between the phases $\mathrm{B}$ and $\mathrm{C}$ takes place for a high efficiency around the second inflexion point of the efficiency sigmoidal curve. 
This phase is therefore beyond the scope of this article, which focuses on modeling deep-bed clogging by nanoparticles, and will be dealt with in another paper. The other two phases are discussed and modeled here.

Phase A: Given the measurement fluctuations, the pressure drop and the efficiency can be considered as constant. Since the deposit is considered as uniform all over the collector's surface, we assumed that the collector diameter increases slightly without significantly blocking the pore space. Therefore, the layer deposited on the collector acts as an impermeable shell (Figure 5). Based on these observations, the equivalent collector diameter used in our model was that of a sphere with the same volume as a collector and its deposit layer. This equivalent collector diameter leads therefore to an increase of the collector diameter and consequently to a decrease of the pressure drop and the efficiency in the model during the phase A. Nevertheless, this raise of the collector's diameter is so small that the related theoretical decreases in pressure drop and efficiency are not perceptible. To determine this volume equivalent diameter, the instantaneous volume of the deposit layer formed during phase A must be calculated:

$$
\mathrm{V}_{\mathrm{d}, \mathrm{c}, \mathrm{A}}=\frac{\mathrm{m}_{\mathrm{p}, \mathrm{c}, \mathrm{A}}}{\rho_{\mathrm{p}}\left(1-\epsilon_{\mathrm{d}}\right)}
$$

where $m_{p, c, A}$ is the instantaneous mass collected per collector during phase $A, \rho_{p}$ is the density of the particulate material, and $\varepsilon_{\mathrm{d}}$ is the deposit's porosity. The deposit's porosity was calculated by applying an empirical correlation, as described in [25]:

$$
\epsilon_{\mathrm{d}}=\frac{1+0.47 \mathrm{Pe}}{1.013+0.5 \mathrm{Pe}}
$$

where Pe is the Péclet number based on the diameter of agglomerates:

$$
\mathrm{Pe}=\frac{\mathrm{Ud}_{\mathrm{me}}}{\mathrm{D}_{\mathrm{Br}}}
$$

with $\mathrm{U}$ as the superficial velocity, and $\mathrm{D}_{\mathrm{Br}}$ as the Brownian diffusivity. 
Therefore, the instantaneous volume of a collector and its deposit can be written as:

$$
\mathrm{V}_{\mathrm{c}, \mathrm{A}}=\frac{\pi \mathrm{d}_{\mathrm{c}}^{3}}{6}+\frac{\mathrm{m}_{\mathrm{p}, \mathrm{c}, \mathrm{A}}}{\rho_{\mathrm{p}}\left(1-\epsilon_{\mathrm{d}}\right)}
$$

where $d_{c}$ is the initial collector diameter. Finally, the instantaneous volume equivalent diameter for the collector can be obtained from:

$$
d_{e q, A}=\left(d_{c}^{3}+\frac{6 m_{p, c, A}}{\pi \rho_{p}\left(1-\epsilon_{d}\right)}\right)^{\frac{1}{3}}
$$

Phase B: The pressure drop and the efficiency increase dramatically. This sharp increase was assigned to an increase in the specific area of the collectors because of the deposit accumulated. Nanoparticles' most outstanding feature is their specific area. For example, the specific area of the metallization fumes used in this study was about $78 \mathrm{~m}^{2} / \mathrm{g}$ (i.e., $4.48 \times 10^{8} \mathrm{~m}^{2} / \mathrm{m}^{3}$ ). While the specific area of collectors increased as deposits accumulated, the unblocked pores surface was significantly reduced, causing increased flow resistivity through the pores and thus an increased flow rate through the deposited layer during this phase. To account for these effects, we decided to use an equivalent collector diameter related to the specific area. This diameter was defined as the diameter of the sphere with the same specific area as a collector and its deposit. As the deposit was considered to be a uniform layer all over the collector's surface (with a thickness $\beta$ ), a threshold thickness of the deposit layer ( $\left.\beta^{*}\right)$ was added to the model as a transition criterion between phases A and B.

To calculate this collector equivalent diameter, the geometric structure of the elements composing the deposit must be known. Some authors assumed a dendritic pattern of nanoparticle deposits [25,26]. In line with this theory, the deposit per collector was defined as a set of cylinders with the same diameter as the collected agglomerates and a length equal to the instantaneous thickness of the layer deposited on the impermeable shell formed during phase A (Figure 5). In this representation, the dimensions of the deposit structures improving the collection efficiency are of the same order of magnitude as those of the agglomerates composing the aerosol. This approach is consistent with the fact that, because of their size, agglomerates cannot physically penetrate the intra-aggregate space of the deposit. 
Indeed, the agglomerates retained form stacks of very small primary particles with internal porosity which is not available as a collection surface.

To calculate the collector specific area, the total surface of the deposit must be known. According to the description of the deposit, its surface can be schematically calculated as the sum of the cylinder areas. This calculation requires information on the number of cylinders and the thickness of the deposited layer considered during phase B. The calculation can be simplified by assuming that all the cylinders are equivalent to a longer one of the same diameter but containing all the particles deposited since the start of phase B (Figure 5) - we called this a Long Equivalent Cylinder or LEC. The instantaneous volume of the LEC can be calculated by:

$$
\mathrm{V}_{\mathrm{LEC}}=\frac{\mathrm{m}_{\mathrm{p}, \mathrm{c}, \mathrm{B}}}{\rho_{\mathrm{p}}}
$$

where $\mathrm{m}_{\mathrm{p}, \mathrm{c}, \mathrm{B}}$ is the instantaneous mass collected per collector in phase B. Therefore, the length of the LEC can be calculated from:

$$
\frac{\mathrm{m}_{\mathrm{p}, \mathrm{c}, \mathrm{B}}}{\rho_{\mathrm{p}}}=\frac{\pi \mathrm{d}_{\mathrm{v}, 50}^{2}}{4} \mathrm{l}_{\mathrm{LEC}} \leftrightarrow \mathrm{l}_{\mathrm{LEC}}=\frac{4 \mathrm{~m}_{\mathrm{p}, \mathrm{c}, \mathrm{B}}}{\pi \mathrm{d}_{\mathrm{v}, 50}^{2} \rho_{\mathrm{p}}}
$$

where $d_{v, 50}$ is the median volume equivalent diameter of the collected agglomerates, and $1_{\text {LEC }}$ is the LEC's length. From this length, it is possible to calculate the instantaneous surface of the deposit formed during phase B by applying:

$$
\mathrm{S}_{\mathrm{LEC}}=\pi \mathrm{d}_{\mathrm{v}, 50} \mathrm{l}_{\mathrm{LEC}}
$$

where $\mathrm{S}_{\mathrm{LEC}}$ is the area of the LEC.

The specific area is a ratio of an area to its volume. As the deposit layer increasing the collection efficiency and the pressure drop is porous, its volume was defined as the volume of the collector and its deposit taking into account the porosity of the layer deposited. The specific area calculated was that of a porous medium, thus considering the collector and its deposit as a unit porous medium (UPM). 
The volume of one UPM is the sum of the volumes of the deposit and of the clean collector:

$$
\mathrm{V}_{\mathrm{UPM}}=\frac{\pi}{6} \mathrm{~d}_{\mathrm{eq}, \mathrm{A}}^{3}+\frac{\mathrm{m}_{\mathrm{p}, \mathrm{c}, \mathrm{B}}}{\rho_{\mathrm{p}}\left(1-\epsilon_{\mathrm{d}}\right)}
$$

As the surface of the equivalent collector at the end of phase $A, S_{\mathrm{eq}, \mathrm{A}}$, is known, the specific area of a UPM can be determined from:

$$
\mathrm{a}_{\mathrm{UPM}}=\frac{\left(\mathrm{S}_{\mathrm{eq}, \mathrm{A}}+\mathrm{S}_{\mathrm{LEC}}\right)}{\mathrm{V}_{\mathrm{UPM}}}=\left(\frac{6 \pi \mathrm{d}_{\mathrm{eq}, \mathrm{A}}^{2} \rho_{\mathrm{p}}\left(1-\epsilon_{\mathrm{d}}\right) \mathrm{d}_{\mathrm{v}, 50}+24\left(1-\epsilon_{\mathrm{d}}\right) \mathrm{m}_{\mathrm{p}, \mathrm{c}, \mathrm{B}}}{\pi \mathrm{d}_{\mathrm{eq}, \mathrm{A}}^{3} \rho_{\mathrm{p}}\left(1-\epsilon_{\mathrm{d}}\right) \mathrm{d}_{\mathrm{v}, 50}+6 \mathrm{~d}_{\mathrm{v}, 50} \mathrm{~m}_{\mathrm{p}, \mathrm{c}, \mathrm{B}}}\right)
$$

Finally, the diameter of a clean collector with the same specific area as a UPM can be calculated by applying:

$$
d_{e q, B}=\frac{6}{a_{U P M}}=\left(\frac{\pi d_{e q, A}^{3} \rho_{p}\left(1-\epsilon_{d}\right) d_{v, 50}+6 d_{v, 50} m_{p, c, B}}{\pi d_{e q, A}^{2} \rho_{p}\left(1-\epsilon_{d}\right) d_{v, 50}+4\left(1-\epsilon_{d}\right) m_{p, c, B}}\right)
$$

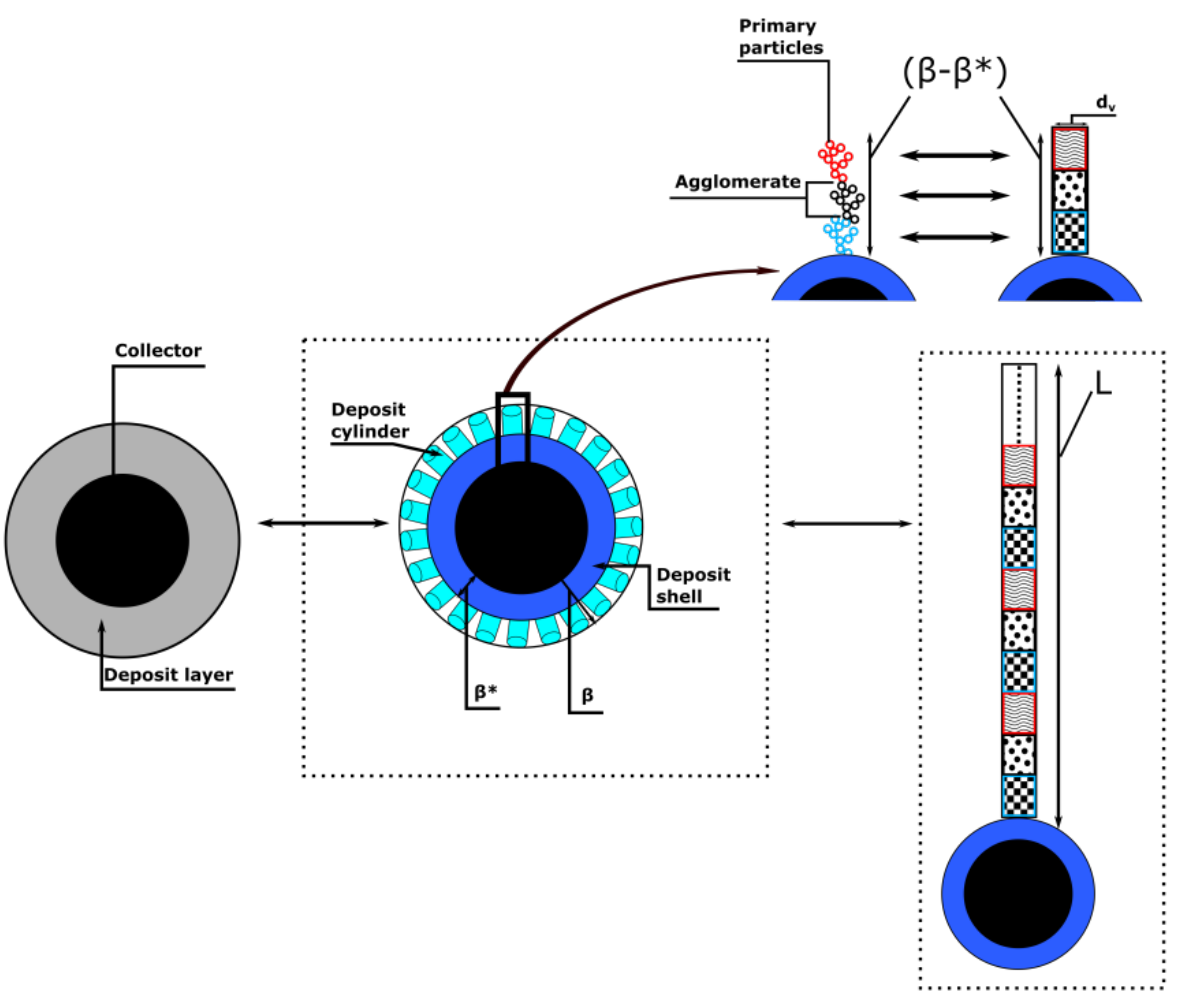

Figure 5 Schematic representation of the deposit formed on a collector during phases $A$ and $B$ 
The equations 13 and 19 permit to obtain equivalent clean collector diameters as a function of the collected mass during the phase A and B. Thus, one can apply initial state models to the obtained virtual clean granular bed and so calculate the pressure drop and efficiency temporal evolutions. The models of initial pressure drop and efficiency used in this study are presented below.

\subsection{Initial state models}

\subsubsection{Efficiency}

The mean electrical mobility-equivalent diameter of the aerosols considered was between 60 and 100 $\mathrm{nm}$, we therefore neglected inertial impaction and sedimentation and only considered Brownian diffusion and interception as collection mechanisms.

- Initial collection efficiency by Brownian diffusion

Brownian motion or Brownian diffusion is the random motion of particles resulting from collisions with molecules of the fluid surrounding them. For particles with a diameter of less than $100 \mathrm{~nm}$, this mechanism is significant. The intensity of Brownian diffusion is given by the Péclet number, the ratio of the convective transfer rate to the diffusive transfer rate. Thus, the efficiency of a single collector due to Brownian diffusion depends on this dimensionless number and is expressed as described in [27] by:

$$
\eta_{\mathrm{Br}}=3.998 \mathrm{~g}_{\mathrm{lam}} \mathrm{Pe}-\frac{2}{3}
$$

where Pe is the Péclet number for a given collector diameter, and $\mathrm{g}_{\text {lam }}$ is known as the laminar hydrodynamic factor and depends only on the porosity of the granular bed. The value of $\mathrm{g}_{\text {lam }}$ depends on the flow model and the way it takes the influence of neighboring collectors into account. Several expressions to determine the value of this parameter can be found in the literature[28-33], three of which were used in this study (Table 2). 


\begin{tabular}{|c|c|}
\hline $\begin{array}{c}\text { Flow models } \\
\text { (quoted in [31] })\end{array}$ & Hydrodynamic factors \\
\hline Tam & $\left(\frac{2+1.5\left(1-\epsilon_{\mathrm{GB}}\right)+1.5\left(8\left(1-\epsilon_{\mathrm{GB}}\right)-3\left(1-\epsilon_{\mathrm{GB}}\right)^{2}\right)^{\frac{1}{2}}}{\epsilon_{\mathrm{GB}}\left(2-3\left(1-\epsilon_{\mathrm{GB}}\right)\right)}\right)^{\frac{1}{3}}$ \\
\hline Neale and Nader & $\frac{1.31}{\epsilon_{\mathrm{GB}}}$ \\
\hline $\begin{array}{c}\text { Wilson and } \\
\text { Geankoplis }\end{array}$ & $\frac{1.09}{\epsilon_{\mathrm{GB}}}$ \\
\hline
\end{tabular}

Table 2 Expressions used in this study to determine the value of the hydrodynamic factor

- Initial collection efficiency by interception

The interception mechanism is related to the finite size of particles, it is significant for particles with diameters between around $100 \mathrm{~nm}$ and $1 \mu \mathrm{m}$. Under this mechanism, a particle following a streamline will be captured if it approaches the collector at a distance measuring less than its radius. This phenomenon is described by the interception parameter, $\mathrm{R}$, defined as the ratio of the particle diameter to the collector diameter. For interception parameters lower than 0.01 , single collector efficiency models based on particle trajectories calculated for the chosen flow model have been described [33]:

$$
\eta_{\mathrm{R}}=1.5 \mathrm{~g}_{\mathrm{lam}}^{3} \mathrm{R}^{2}
$$

If the unit collector efficiency for the different mechanisms is known, the overall efficiency of a collector can be determined from:

$$
\eta_{\mathrm{T}}=1-\left(1-\eta_{\mathrm{Br}}\right)\left(1-\eta_{\mathrm{R}}\right)
$$

Then, the efficiency of the granular bed can be calculated by applying the following equation:

$$
\mathrm{E}_{\mathrm{th}}=1-\exp \left(-\frac{3}{2}\left(\frac{1-\epsilon_{\mathrm{GB}}}{\mathrm{d}_{\mathrm{c}}}\right) \mathrm{z}_{\mathrm{GB}} \eta_{\mathrm{T}}\right)
$$

where $\mathrm{z}_{\mathrm{GB}}$ is the depth of the granular bed considered. 


\subsubsection{Pressure drop}

In the case of aerosol filtration by granular beds, the flow regime is more often laminar or slightly intermediate rather than turbulent. The regime is indicated by the value of the Reynolds number for the packed beds:

$$
\operatorname{Re}=\frac{\rho_{\mathrm{fl}} \mathrm{Ud}_{\mathrm{c}}}{\mu\left(1-\epsilon_{\mathrm{GB}}\right)}
$$

where $\rho_{\mathrm{fl}}$ is the fluid density, and $\mu$ is the dynamic viscosity of the fluid. Flow is laminar up to a value of 10 and is fully turbulent at values greater than 2000. In our case, the packed bed Reynolds number did not exceed 20; therefore, we assumed that the laws for laminar flow were always valid during the initial state. The formula most commonly used to determine the pressure drop in this regime is the Kozeny-Carman equation [34]:

$$
\Delta \mathrm{P}=36 \mathrm{~h}_{\mathrm{k}} \mu \mathrm{U}\left(\frac{\left(1-\epsilon_{\mathrm{GB}}\right)^{2}}{\epsilon_{\mathrm{GB}}^{3}}\right)\left(\frac{\mathrm{z}_{\mathrm{GB}}}{\mathrm{d}_{\mathrm{c}}^{2}}\right)
$$

where $h_{k}$ is the Kozeny-Carman constant which can be written as a function of the granular bed's porosity as follows:

$$
\mathrm{h}_{\mathrm{k}}=5+\exp \left(14\left(\epsilon_{\mathrm{GB}}-0.8\right)\right)
$$

\subsection{Model calculations}

\subsubsection{Main features}

The equations presented above linking the mass collected to the different equivalent collector diameters were implemented in a Matlab ${ }^{\circledR}$ code with two important features. First, the granular bed was spatially discretized. Indeed, since the deposit is not uniform throughout the granular bed, this latter must be discretized in layers perpendicular to the direction of the flow field. The depth of a discretization stage depends only on the initial collector diameter and for our purposes was chosen equal to one collector diameter. The second important feature is the use of a volume equivalent diameter for agglomerates. 
To test the various efficiency models, agglomerates were considered as spheres composed of the same volume of material. This volume equivalent diameter was chosen so that the modeled deposit comprised the same amount of material as the experimental deposit.

\subsubsection{Numerical scheme}

The pressure drop and the collection efficiency were initialized with the values calculated for the clean granular bed using the initial efficiency and pressure drop models. The mass particle size distribution was maintained constant at the inlet of the first layer of the discretized granular bed. The collection efficiency for different particle sizes was then calculated along with the corresponding mass deposited in this first layer for a defined time interval. Knowing the efficiency of this layer, it was possible to determine the composition of the aerosol entering the next layer and the mass of each size of particle retained by applying the same approach as for the first layer. The procedure was repeated for all subsequent layers. For each of them, the thickness $(\beta)$ of the deposit layer per collector is calculated as the difference between the radius of the sphere having the same volume as the set collector/deposit (including porosity) and the initial collector radius. The volume of a collector and its deposit must be calculated using the equations 9 to 12 at any time of the filtration process. Then, $\beta$ is compared to the critical deposit layer thickness ( $\left.\beta^{*}\right)$. As long as $\beta$ is smaller than $\beta^{*}$, the phase $\mathrm{A}$ is running. The phase $\mathrm{B}$ begins in a given discretization layer from the moment when $\beta$ becomes larger than $\beta^{*}$. Thus, all these layers do not enter the phase B at the same time. The mass fraction of deposited particles was used to calculate the mean diameter of the agglomerates composing the deposit and to obtain the new collector equivalent diameter for each layer, and thus to determine the instantaneous mass efficiency and pressure drop. The collector equivalent diameters are calculated by the equations 13 and 19 during the phases A and B, respectively. This procedure was then repeated for the next time interval until the total modeling time was reached. 


\section{Results and discussion}

In order to validate our model, its predictions are compared in this section with the results obtained from various experiments performed on granular beds having a depth of $11 \mathrm{~mm}$ (for complete operating conditions see table 1).

\subsection{Transition factor $(\beta *)$}

The transition factor, $\beta^{*}$, corresponds to the amount of deposit beyond which a significant effect on pressure drop and efficiency was observed. From the conceptual representation of the collectors and their deposit, it was convenient to express this critical collected mass as a threshold thickness of the deposit layer all over the collector's surface (Figure 6). During clogging, the airflow is divided between the free pore space and the deposit depending on their respective flow resistances. Thus, $\beta^{*}$ can intuitively be assumed to correlate with the permeability of the granular bed $\left(\mathrm{K}_{\mathrm{GB}}\right)$ and of the deposit $\left(\mathrm{K}_{\mathrm{d}}\right)$. These permeabilities were calculated by applying the Kozeny-Carman law and a pressure drop model for nanostructured deposits [25], respectively. The flow resistances of the deposit and of the free pore space depend directly on the volume occupied by the deposit. This volume is linked to the calculated mass of particles collected by the deposit's porosity and the density of the particulate material. Porosity of the deposit is directly considered when calculating the deposit's permeability, it was therefore assumed that $\beta^{*}$ should also be a function of the particulate material's density. Applying these assumptions, a linear correlation (Equation 27) was observed between the parameters described above and the $\beta^{*}$ values determined by fitting the model to the experimental results (Figure 6).

$$
\beta^{*} \rho_{p}=5.03 .10^{-11}\left(\frac{\mathrm{K}_{\mathrm{GB}}}{\mathrm{K}_{\mathrm{d}}}\right)+2.13 .10^{-4}
$$




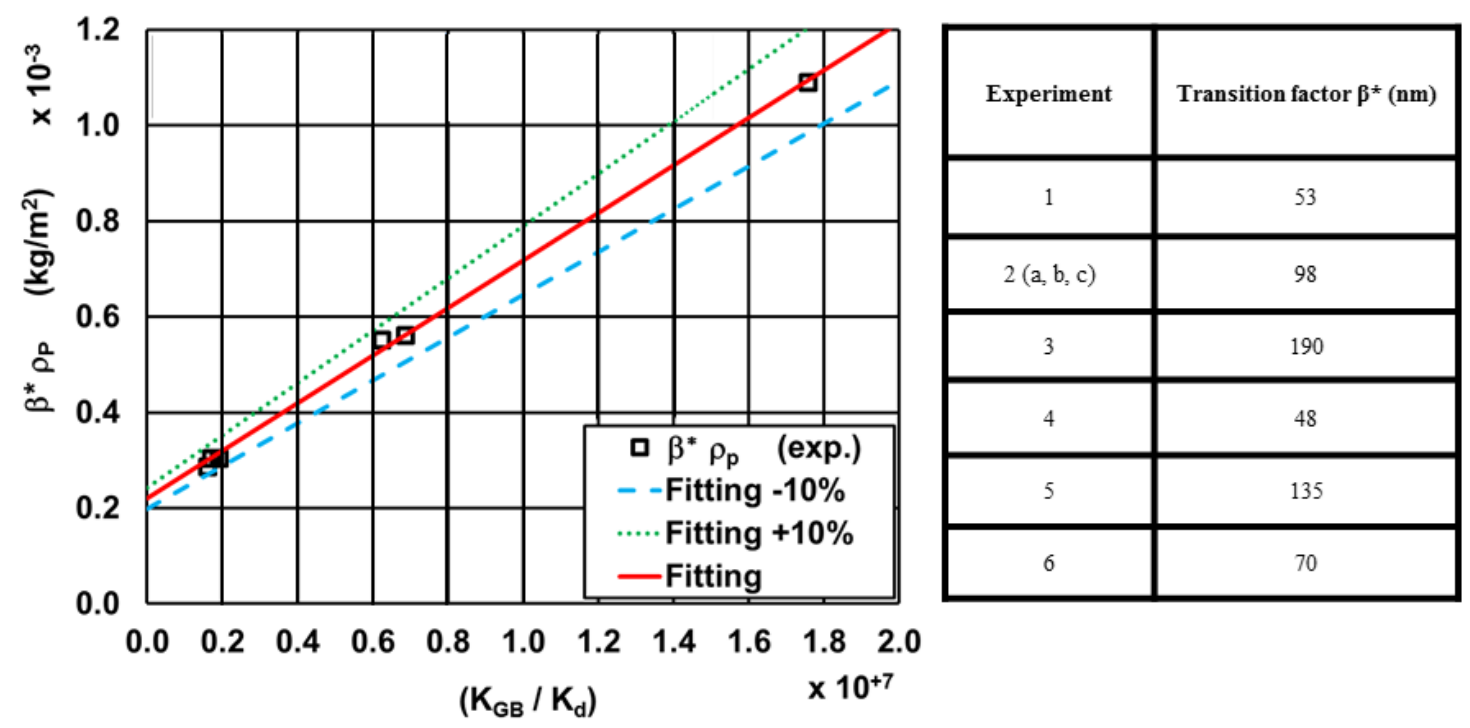

Figure 6 Transition factor, $\beta^{*}$, as a function of the material density and the ratio of granular bed and deposit permeabilities

\subsection{Efficiency}

The experimental efficiencies were compared to the theoretical results obtained using the efficiency models described previously. The Figure 7, representing these efficiencies as a function of the collected mass per unit porous volume (i.e. the ratio between the collected mass and the void volume of the granular bed), shows a good agreement between experimental data and model-based predictions, particularly in the cases of zinc-aluminum aerosols. These data also demonstrated that the model was valid for all the collector sizes, particle properties and fluid superficial velocities tested (Table 2).

Despite the trend for good agreement between experimental data and the model-based predictions, a slight difference was observed with carbon and iron particles. These differences were caused by a lack of precision in the initial efficiency model. Indeed, a slight underestimation of the initial collection efficiency was noted with carbon and iron particles (Figure 7). It should also be noted that the single initial efficiency model allowing the best predictions for each set of operating conditions is difficult to identify. Nevertheless, the use of the hydrodynamic factors presented by Tam and Wilson \& Geankoplis led, respectively, to an overestimated and an underestimated solution. These solutions generally bounded the experimental data and those obtained Neale-Nader hydrodynamic factor. 
Furthermore, data obtained from experiments using the same operating conditions showed the same overall trend, but the precise values could vary significantly from one experiment to another at high efficiency. Based on these observations, we recommend the use of the Neale-Nader hydrodynamic factor. In most cases, this factor provides a relatively good estimation of efficiency over time.
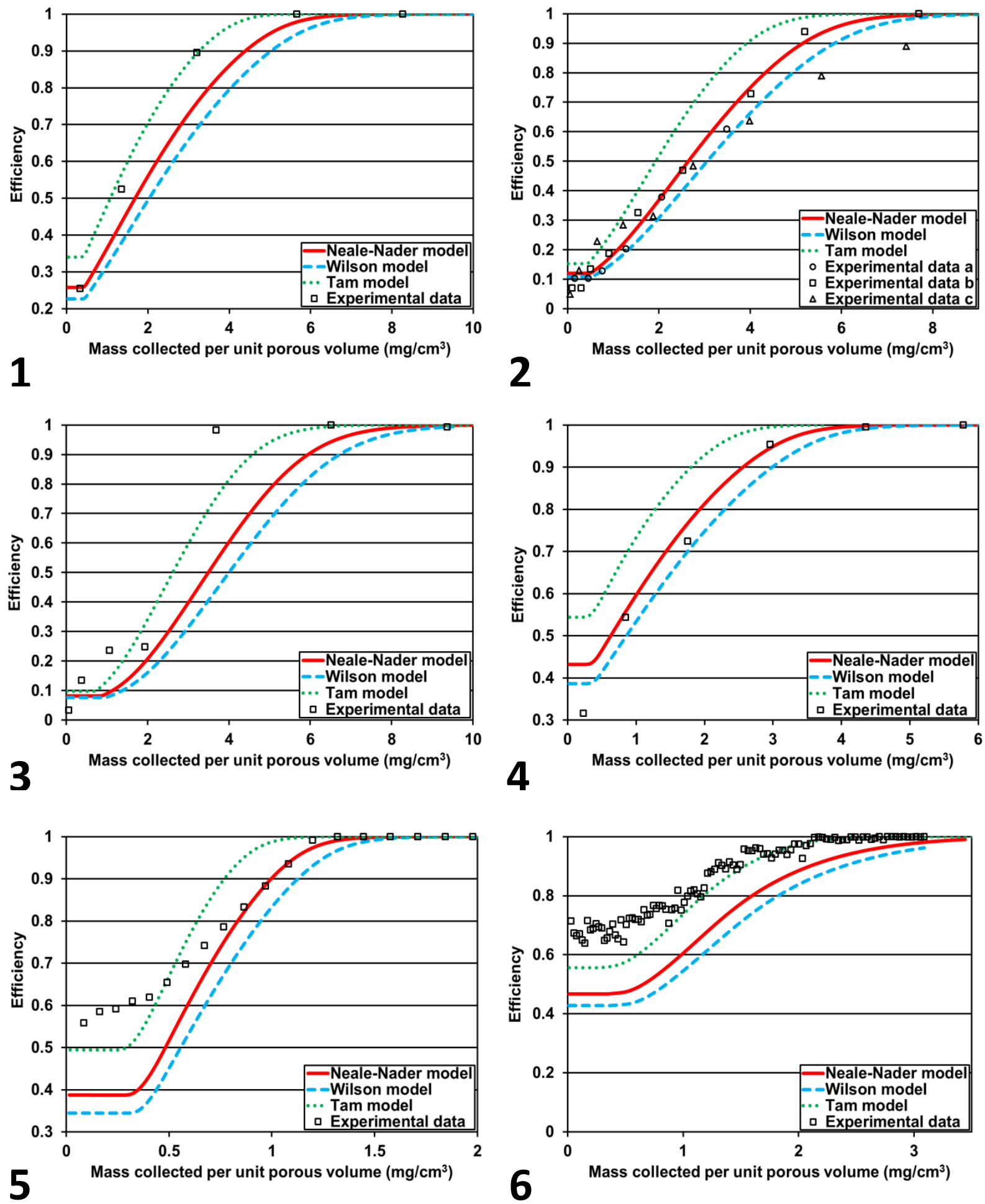

Figure 7 Comparison of the efficiency model with experimental data (experiments 1,2,3,4,5,6) 
As this efficiency model is based on the discretization of the granular bed in thin layers, it was also possible to establish the theoretical penetration profiles resulting in the masses collected at different depths of the granular bed. As previously observed experimentally at a larger scale [1], the penetration profile shown in Figure 8 indicates that, after a short clogging time, the greatest fraction of the instantaneous mass per porous volume unit was collected in the very first millimeters of the granular bed. These penetration profiles are qualitatively consistent with those obtained by Gitis et al. (2010) in their deep-bed liquid filtration model based on 3 successive deposition kinetics [35]. Since a same but differently distributed collected mass does not generate the same pressure drop, it is very important to take into account these penetration profiles to model how pressure drop was affected during clogging.

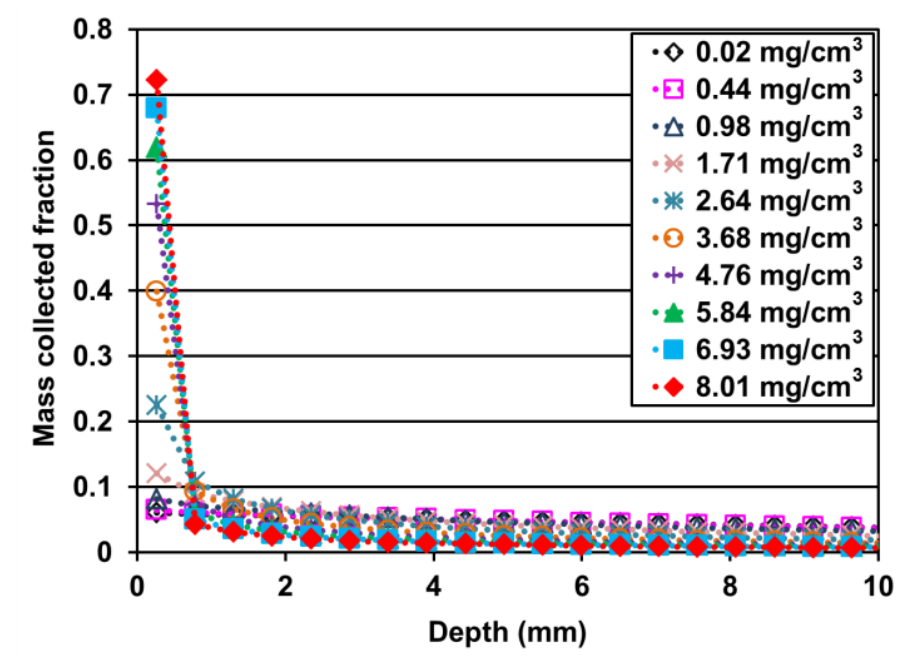

Figure 8 Theoretical penetration profiles for experiment 4

(Collector diameter: $0.5 \mathrm{~mm} /$ Particulate material: $\mathrm{Zn}$-Al / Superficial velocity: $7.49 \mathrm{~cm} / \mathrm{s}$ )

\subsection{Pressure drop}

The experimental pressure drops obtained from the same set of experiments were also compared to the theoretical results (Figure 9). The curves on these graphs represent the pressure drops during phases A and $\mathrm{B}$, calculated using the penetration profiles obtained from the efficiency models presented above. Good agreement was found between the experimental data and our model. The observations made for the efficiency models were also valid for the pressure drop. Thus, the results obtained with the Tam and Wilson-Geankoplis hydrodynamic factors continued to represent a maximum and a minimum solution, respectively. 
And once again, applying the Neale-Nader hydrodynamic factor provided a fairly good approximation of how pressure drop changes during clogging. This result is consistent with the previous conclusions for the efficiency model and implies that the same hydrodynamic factor can be used to satisfactorily model both the efficiency and the pressure drop.
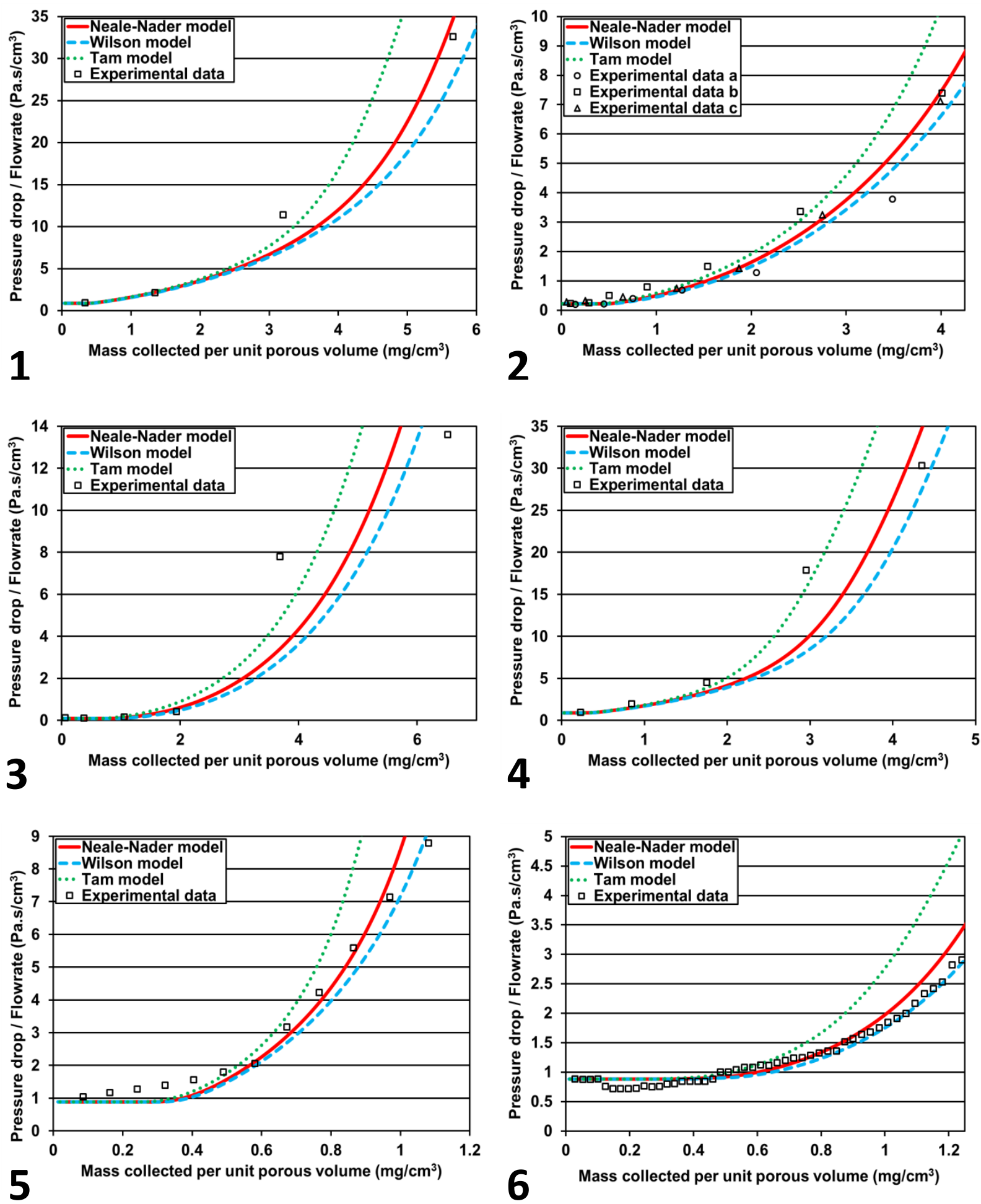

Figure 9 Comparison of the pressure drop model and experimental data (experiments 1,2,3,4,5,6) 
Some comparisons in terms of pressure drop and efficiency with results obtained in the same operating conditions as the experiment $\mathrm{n}^{\circ}=1$ but for a larger depth $(33 \mathrm{~mm})$ also showed a good agreement. Furthermore, it must be noticed in this last case that, a permeability being not dependent on the depth of a given porous media, the value used for $\beta^{*}$ is the same as the one of the experiment $n^{\circ}=1$.

\section{Conclusions}

In this article we present a new model to describe clogging of a granular bed. The model was based on previously published initial efficiency and pressure drop models. It was developed, by calculating several collector equivalent diameters depending on the mass retained per collector. Clogging was divided into phases $(\mathrm{A}, \mathrm{B}, \mathrm{C})$ representing three different kinetics, and the deposit was assumed to form a uniform layer all over the collector's surface. Phase A of clogging was described by a volume equivalent diameter where the deposit was considered to be an impermeable shell, while phase B was modeled by a specific area equivalent diameter. According to the representation of the deposit on the collectors used, a threshold thickness $\left(\beta^{*}\right)$ of the deposit layer was chosen as the transition criterion between phases A and B. This criterion was calculated by a semi-empirical correlation established as a function of the permeability of the deposit and the granular bed, and of the particles' material density. Through this approach, the efficiency and pressure drop during the first two phases of deep-bed clogging were successfully modeled. Thus, beyond predicting changes to efficiency over time, this model also provided theoretical penetration profiles giving access to the mass deposited at different locations in the granular bed. This was a key step in calculating how the pressure drop changed during clogging.

For filtration efficiency in the third phase (C), further modeling is not necessary since its maximum value was reached in phase B. However, as the pressure drop starts to increase linearly in phase C, a new model will need to be developed. The behavior in this phase was assigned to the full blockage of the pores constrictions in the first granular bed discretization, which marks the start of the surface filtration phase. Therefore, this phase should be described by a pore approach rather than a collector one. 


\section{Nomenclature}

\section{Letters}

\begin{tabular}{|c|c|c|}
\hline $\mathrm{a}$ & Specific area & $\left(\mathrm{m}^{2} / \mathrm{m}^{3}\right)$ \\
\hline$d$ & Diameter & $(\mathrm{m})$ \\
\hline $\mathrm{C}$ & Concentration & $\left(/ \mathrm{m}^{3}\right.$ or $\left.\mathrm{kg} / \mathrm{m}^{3}\right)$ \\
\hline $\mathrm{D}$ & Diffusivity & $\left(\mathrm{s} / \mathrm{m}^{2}\right)$ \\
\hline $\mathrm{E}$ & Granular bed efficiency & $(-)$ \\
\hline $\mathrm{g}_{\text {lam }}$ & Hydrodynamic factor & $(-)$ \\
\hline$h_{k}$ & Kozeny-Carman constant & $(-)$ \\
\hline K & Permeability & $\left(m^{2}\right)$ \\
\hline 1 & Length & $(\mathrm{m})$ \\
\hline $\mathrm{m}$ & Mass & $(\mathrm{kg})$ \\
\hline $\mathrm{Pe}$ & Péclet number & $(-)$ \\
\hline $\mathrm{Q}$ & Volumetric flowrate & $\left(\mathrm{m}^{3} / \mathrm{s}\right)$ \\
\hline $\mathrm{R}$ & Interception parameter & $(-)$ \\
\hline $\mathrm{Re}$ & Packed bed Reynolds number & $(-)$ \\
\hline $\mathrm{S}$ & Surface & $\left(\mathrm{m}^{2}\right)$ \\
\hline $\mathrm{U}$ & Superficial velocity & $(\mathrm{m} / \mathrm{s})$ \\
\hline $\mathrm{V}$ & Volume & $\left(\mathrm{m}^{3}\right)$ \\
\hline $\mathrm{z}$ & Depth & $(\mathrm{m})$ \\
\hline
\end{tabular}




\section{Greek letters}

$\beta \quad$ Deposit thickness $\quad(\mathrm{m})$

$\Delta \mathrm{P} \quad$ Pressure drop $\quad(\mathrm{Pa})$

$\varepsilon \quad$ Porosity

$\mu \quad$ Dynamic viscosity $\quad$ (Pa.s)

$\eta \quad$ Single collector efficiency $\quad(-)$

$\rho$ Density $\quad\left(\mathrm{kg} / \mathrm{m}^{3}\right)$

\section{Subscript}

\begin{tabular}{|c|c|c|c|}
\hline A & Clogging phase A & LEC & Long Equivalent Cylinder \\
\hline agg & Agglomerates & $\mathrm{m}$ & Mass \\
\hline B & Clogging phase B & me & Electrical mobility \\
\hline $\mathrm{Br}$ & Brownian diffusion & $\mathrm{n}$ & Number \\
\hline $\mathrm{c}$ & Collector & $\mathrm{p}$ & Collected particles \\
\hline $\mathrm{d}$ & Deposit (including its porosity) & $\mathrm{R}$ & Interception \\
\hline down & Downstream & real & Real experimental value \\
\hline $\mathrm{e}$ & Effective value & $\mathrm{T}$ & Total (all considered collection \\
\hline eq & Equivalent collector & & mechanisms or total collected mass) \\
\hline $\exp$ & experimental & th & Theoretical \\
\hline f & Gravimetric measurement & up & Upstream \\
\hline $\mathrm{fl}$ & Fluid & UPM & Unit Porous Media \\
\hline GB & Granular bed & & Volume \\
\hline
\end{tabular}

i Particle size or Nanoscan channel 


\section{References}

[1] D. Bémer, I. Subra, Y. Morele, A. Charvet, D. Thomas, Experimental study of granular bed filtration of ultrafine particles emitted by a thermal spraying process, J. Aerosol Sci. 63 (2013) 25-37. doi:10.1016/j.jaerosci.2013.04.005.

[2] J.P. Herzig, D.M. Leclerc, P. Le Goff, Flow of Suspensions through Porous Media-Application to Deep Filtration, Ind. Eng. Chem. 62 (1970) 8-35. doi:10.1021/ie50725a003.

[3] J.P. Herzig, D.M. Leclerc, P. Le Goff, Flow of Suspensions through Porous Media-Application to Deep Filtration, Ind. Eng. Chem. 62 (1970) 8-35. doi:10.1021/ie50725a003.

[4] C. Tien, B.V. Ramarao, Granular Filtration of Aerosols and Hydrosols, Elsevier, 2011.

[5] S.A. Walata, T. Takahashi, C. Tien, Effect of Particle Deposition on Granular Aerosol Filtration: A Comparative Study of Methods in Evaluating and Interpreting Experimental Data, Aerosol Sci. Technol. 5 (1986) 23-37. doi:10.1080/02786828608959074.

[6] T. Takahashi, S.A. Walata, C. Tien, Transient behavior of granular filtration of aerosols-effect of aerosol deposition on filter performance, AIChE J. 32 (1986) 684-690. doi:10.1002/aic.690320420.

[7] Y. Jung, C. Tien, New correlations for predicting the effect of deposition on collection efficiency and pressure drop in granular filtration, J. Aerosol Sci. 22 (1991) 187-200. doi:10.1016/00218502(91)90027-F.

[8] C.R. O'Melia, W. Ali, The role of retained particles in deep bed filtration, in: Prog. Water Technol., 1978.

[9] C. Tien, R.M. Turian, H. Pendse, Simulation of the dynamic behavior of deep bed filters, AIChE J. 25 (1979) 385-395. doi:10.1002/aic.690250302.

[10] J. Happel, Viscous flow in multiparticle systems: Slow motion of fluids relative to beds of spherical particles, AIChE J. 4 (1958) 197-201. doi:10.1002/aic.690040214.

[11] A. Payatakes, A New Model for Granular Porous Media: Applications to Filtration Through Packed Beds, Syracuse University, 1973. http://books.google.fr/books?id=IZJQAQAAIAAJ.

[12] C.U. Choo, C. Tien, Analysis of the Transient Behavior of Deep-Bed Filtration, J. Colloid Interface Sci. 169 (1995) 13-33. doi:10.1006/jcis.1995.1002.

[13] M. Fichman, C. Gutfinger, D. Pnueli, Effect of particle loading on granular bed filtration-The cluster enhanced filter model, J. Aerosol Sci. 19 (1988) 425-441. doi:10.1016/00218502(88)90018-3.

[14] C.U. Choo, C. Tien, Simulation of hydrosol deposition in granular media, AIChE J. 41 (1995) 1426-1442. doi:10.1002/aic.690410609.

[15] S. Vigneswaran, C. Tien, Transient behavior of deep-bed filtration of brownian particles, Chem. Eng. Sci. 42 (1987) 2729-2739. doi:10.1016/0009-2509(87)87023-9.

[16] J. Koplik, Creeping flow in two-dimensional networks, J. Fluid Mech. 119 (1982) 219-247. doi:10.1017/S0022112082001323.

[17] H. Pendse, C. Tien, A simulation model of aerosol collection in granular media, J. Colloid Interface Sci. 87 (1982) 225-241. doi:10.1016/0021-9797(82)90385-X.

[18] H.W. Chiang, C. Tien, Dynamics of deep-bed filtration. Part I: Analysis of two limiting situations, AIChE J. 31 (1985) 1349-1359. doi:10.1002/aic.690310814.

[19] V.N. Burganos, E.D. Skouras, C.A. Paraskeva, A.C. Payatakes, Simulation of the dynamics of depth filtration of non-Brownian particles, AIChE J. 47 (2001) 880-894. doi:10.1002/aic.690470411.

[20] E.D. Skouras, V.N. Burganos, C.A. Paraskeva, A.C. Payatakes, Simulation of downflow and upflow depth filtration of non-Brownian particles under constant flowrate or constant pressure drop conditions, J. Chin. Inst. Chem. Eng. 35 (2004) 87-100.

[21] P.F. DeCarlo, J.G. Slowik, D.R. Worsnop, P. Davidovits, J.L. Jimenez, Particle Morphology and Density Characterization by Combined Mobility and Aerodynamic Diameter Measurements. Part 1: Theory, Aerosol Sci. Technol. 38 (2004) 1185-1205. doi:10.1080/027868290903907.

[22] A. Charvet, S. Bau, N.E.P. Coy, D. Bémer, D. Thomas, Characterizing the effective density and primary particle diameter of airborne nanoparticles produced by spark discharge using mobility 
and mass measurements (tandem DMA/APM), J. Nanoparticle Res. 16 (2014) 1-11. doi:10.1007/s11051-014-2418-y.

[23] A. Charvet, S. Bau, D. Bémer, D. Thomas, On the Importance of Density in ELPI Data PostTreatment, Aerosol Sci. Technol. 49 (2015) 1263-1270. doi:10.1080/02786826.2015.1117568.

[24] A. Charvet, L. Wingert, N. Bardin-Monnier, S. Pacault, C. Godoy, Q. Ribeyre, D. Thomas, Visualization of airborne nanoparticle deposits onto spherical collectors, Sep. Purif. Technol. 172 (2017) 119-129. doi:10.1016/j.seppur.2016.07.045.

[25] D. Thomas, F.X. Ouf, F. Gensdarmes, S. Bourrous, L. Bouilloux, Pressure drop model for nanostructured deposits, Sep. Purif. Technol. 138 (2014) 144-152. doi:10.1016/j.seppur.2014.09.032.

[26] A.C. Payatakes, L. Gradon, Dendritic deposition of aerosols by convective Brownian diffusion for small, intermediate and high particle Knudsen numbers, AIChE J. 26 (1980) 443-454. doi:10.1002/aic.690260316.

[27] J.R. Coury, K.V. Thambimuthu, R. Clift, Capture and rebound of dust in granular bed gas filters, Powder Technol. 50 (1987) 253-265. doi:10.1016/0032-5910(87)80071-2.

[28] E.J. Wilson, C.J. Geankoplis, Liquid Mass Transfer at Very Low Reynolds Numbers in Packed Beds, Ind. Eng. Chem. Fundam. 5 (1966) 9-14. doi:10.1021/i160017a002.

[29] G.H. Neale, W.K. Nader, Prediction of transport processes within porous media: Creeping flow relative to a fixed swarm of spherical particles, AIChE J. 20 (1974) 530-538. doi:10.1002/aic.690200314.

[30] C.K.W. Tam, The drag on a cloud of spherical particles in low Reynolds number flow, J. Fluid Mech. 38 (1969) 537-546. doi:10.1017/S0022112069000322.

[31] G.I. Tardos, C. Gutfinger, N. Abuaf, High peclet number mass transfer to a sphere in a fixed or fluidized bed, AIChE J. 22 (1976) 1147-1150. doi:10.1002/aic.690220629.

[32] G.I. Tardos, N. Abuaf, C. Gutfinger, Dust Deposition in Granular Bed Filters: Theories and Experiments, J. Air Pollut. Control Assoc. 28 (1978) 354-363. doi:10.1080/00022470.1978.10470610.

[33] C. Gutfinger, G.I. Tardos, Theoretical and experimental investigation on granular bed dust filters, Atmospheric Environ. 1967. 13 (1979) 853-867. doi:10.1016/0004-6981(79)90276-2.

[34] C. Tien, B.V. Ramarao, Can filter cake porosity be estimated based on the Kozeny-Carman equation?, Powder Technol. 237 (2013) 233-240. doi:10.1016/j.powtec.2012.09.031.

[35] V. Gitis, I. Rubinstein, M. Livshits, G. Ziskind, Deep-bed filtration model with multistage deposition kinetics, Chem. Eng. J. 163 (2010) 78-85. doi:10.1016/j.cej.2010.07.044. 